\title{
Effects of Leader Tactics on the Creativity, Implementation, and Evolution of Ideas to Improve Healthcare Delivery
}

\author{
Yuna S. H. Lee, PhD, MPH ${ }^{\top}$, Paul D. Cleary, PhD'², and Ingrid M. Nembhard, PhD, MS ${ }^{3}$ \\ ${ }^{1}$ Columbia University Mailman School of Public Health, New York, NY, USA; ${ }^{2}$ Yale School of Public Health, New Haven, CT, USA; ${ }^{3}$ The Wharton School, \\ University of Pennsylvania, Philadelphia, PA, USA.
}

\begin{abstract}
BACKGROUND: Slow progress in quality improvement (QI) has prompted calls to identify new QI ideas. Leaders guiding these efforts are advised to use evidence-based tactics, or specific approaches to address a goal, to promote clinician and staff engagement in the generation and implementation of QI ideas, but little evidence about effective tactics exists.
\end{abstract}

OBJECTIVE: Examine the association between leader tactics and the creativity, implementation outcome, and evolution of QI ideas from clinicians and staff.

DESIGN: Prospective panel analysis of 220 ideas generated by 12 leaders and teams ( $N=72$ members) from federally qualified community health practices in one center over 18 months. Measures were extracted from meeting minutes (note-taking by a member during meetings) and expert panel review. Multi-level models were used.

MEASURES: Leader tactics, idea creativity, implementation outcome, evolution pathways, center, and ideasubmitter characteristics.

RESULTS: Leaders used one of four approaches: no tactic, meeting ground rules, team brainstorming, or reflection on team process. Implemented ideas evolved in three pathways: Plug and Play, Slow Burn, and Iterate and Generate. Compared with no leader tactic, meeting ground rules resulted in ideas not significantly different in creativity, implementation outcome, or evolution pathway. Brainstorming was associated with greater idea creativity, idea implementation, and ideas following a Plug and Play path (low member engagement and implementation over 2 months or less). Reflection on team process was associated with idea implementation (versus not), and ideas following an Iterate and Generate path (high member engagement and implementation over 3 months or more).

CONCLUSIONS: Two tactics, brainstorming and reflection, are helpful depending on goals. Brainstorming may aide leaders seeking disruptive change via more creative, rapidly implemented ideas. Reflection on team process may aide leaders seeking high-engagement ideas that may be implemented slowly. Both tactics may help leaders cultivate dynamics that increase implementation of ideas that improve healthcare.

KEY WORDS: quality improvement; implementation; leader; ideas; primary care.

Received September 9, 2019

Accepted August 11, 2020

Published online August 31, 2020
J Gen Intern Med 36(2):341-8

DOI: $10.1007 /$ s11606-020-06139-9

(C) Society of General Internal Medicine 2020

\section{INTRODUCTION}

To achieve the goal of a high-quality, learning healthcare system in the USA, many physicians and leaders endorse the use of quality improvement (QI) methods to assess changes in areas needing improvement. ${ }^{1,2}$ Engaging primary care practices, described as system gatekeepers, ${ }^{3}$ is essential to successful QI efforts focused on improving population health, enhancing patient experiences, and reducing costs. ${ }^{1,2}$ Slow progress in these efforts has prompted calls to identify new ideas for QI, with many suggesting organizations solicit creative ideas from clinicians and staff. Clinicians and staff observe the wide-ranging realities of care, which positions them to generate and implement QI ideas. ${ }^{3,}{ }^{4}$ However, engaging them in QI idea-related processes is challenging given time pressures and workload. 5,6 Often, clinicians and staff are tasked with guiding these efforts, becoming "QI leaders." As QI leaders, they are advised to use evidence-based tactics, or specific approaches to address a goal, to promote engagement in the generation and implementation of QI ideas. ${ }^{7-9}$

Little is known about the tactics that QI leaders can use to solicit creative (defined as novel and useful) ${ }^{10,}{ }^{11}$ QI ideas from primary care clinicians and staff, and nurture such ideas so that they are implemented, providing an opportunity to improve outcomes. ${ }^{9}$ In contrast, research exists on leader behavior, or words and deeds that leaders display during interactions, and styles, or an overall pattern of leader behaviors. ${ }^{12}$ Leader behaviors such as supporting staffs' actions ${ }^{12-14}$ are positively associated with generating creative ideas and idea implementation. Participative leader styles are positively associated with creative idea generation ${ }^{9,15,16}$ and more directive styles with implementation. ${ }^{9}$

For QI leaders seeking to engage primary care clinicians and staff in QI idea-related processes, tactics could be more actionable and effective than leader behaviors and styles due to tactics' focused nature. ${ }^{9}$ QI leader training often focuses on tactics to test interventions, and less on tactics to elicit ideas that form intervention inputs. ${ }^{7}$ An example tactic to elicit ideas is brainstorming, or rapid generation of ideas. ${ }^{8,}{ }^{17}$ While studies have examined the association of brainstorming and 
creativity, ${ }^{18,19}$ no work has assessed the relative effectiveness of leader tactics on idea-related processes. ${ }^{8,} 19$ The study objective was to assess the relationship between leader tactics and the generation of creative ideas, implementation, and evolution of implemented ideas by QI teams, to inform QI leaders' selection of tactics to achieve their goals.

\section{METHODS}

\section{Study Design}

The study was conducted in 12 federally qualified community health practices in one US center over 18 months, serving 130,000 patients annually. Teams at each practice (primary care providers, nurses, behavioral health providers, and medical assistants) were asked to develop QI initiatives. The center assigned leaders from its QI department (nurses or PCPs with a department affiliation) to lead each team. The department provided 25 training hours upon department affiliation, which comprised training from department experts and outside consultants on methods to support improvement, address challenging team dynamics, and facilitate effective meetings. Trainings occurred in person and via video-conference, and all leaders received training prior to the study period. During the study, teams developed and implemented initiatives focused on care coordination. Leaders were encouraged to elicit ideas from team members using tactics taught at the department (meeting ground rules, brainstorming time, and reflection on team process). Leaders were free to choose which tactics they used with their teams, if any, and were in contact with department experts for ongoing support. We analyzed 220 QI ideas generated by teams.

We used two approaches to study leader tactics. The first was qualitative data analysis to identify leader tactics (four identified), ideas generated by teams ( $N=220$ ideas), ideas' creativity and implementation outcome, and evolution pathways for implemented ideas. The second was quantitative analysis of leader tactics and idea creativity, implementation, and evolution.

\section{Data Sources}

QI Team Meeting Minutes. We analyzed minutes from 216 QI team meetings (monthly meetings for 18 months at 12 practices). QI team creation, clinical team roles, care coordination focus, and meeting organization (monthly for 1 $\mathrm{h}$, written minutes taken by a member, and meeting minutes format) were required by the organization. Minutes included practice name, date, attendees, agenda, discussion, action items, and staff responsible. Meeting minutes was the organization's norm and analysis for study purposes was not planned at the time of meetings, eliminating the possibility that leader tactics were influenced by note-taking related to our study. We analyzed minutes using a two-step content analysis process. ${ }^{20,}{ }^{21}$ We identified leader tactics used across the 12 practices. Three tactics were used across nine leaders. Three leaders did not employ any specific tactic. The first author, a $\mathrm{PhD}$-trained researcher with quantitative and qualitative methods expertise, coded QI ideas and the individual(s) who proposed each idea. Ideas were defined as: "A different alternative for a possible course of action to approach the task at hand. ${ }^{22}$ Two MPH-trained researchers independently coded ideas in $30 \%$ and $70 \%$ of the minutes. ${ }^{23}$ There was $83 \%$ and $94 \%$ intercoder reliability between the first and second coders and first and third coders, considered "acceptable" (70\%) to "exceptional" (94\%). ${ }^{24}$ Idea identification discrepancies (5\%) were discussed until consensus was reached. Atlas.ti 8 was used to code.

Staff Work Experience Surveys. We collected survey data on staff characteristics (professional role, tenure, and gender) and practice characteristics (psychologically safe work climate). We recruited and consented participants using leadership emails and meetings with researchers. At the start of the study, we administered the survey via email or paper to all 72 team members in the 12 practices (100\% participation). Participants were full-time employees and majority were female (79\%). The largest group of respondents were nurses (31\%), with PCPs (27\%), medical assistants (23\%), and behavioral health providers (19\%), and $61 \%$ of staff were employed by the organization for more than 2 years.

\section{Measures}

Leader Tactic. The first leader tactic observed was meeting ground rules, or agreed-upon rules about meeting process, participation, and respecting others' opinions. We coded the leader as using this tactic if there was a ground rules discussion in minutes during the first meeting. The second leader tactic was brainstorming time, in which leaders provided team time to generate ideas. We coded a leader as using this tactic when brainstorming time was noted in minutes (this occurred in $100 \%$ of their meetings). The third leader tactic was reflection on team process, which involved leaders dedicating time to reflect collectively on the process in the meeting. Teams discussed whether the team was working effectively, how team members were communicating, and how the team was making decisions. Teams assigned a score out of 10 to the meeting and discussed what they could do to improve. We coded a leader as using this tactic when minutes indicated these discussions (this occurred in $90 \%$ of their meetings). When no tactic was observed, we coded the leader tactic as "no leader tactic" (reference category). No other tactics were mentioned beyond those described. Table 1 displays the tactics. One tactic was identified for each QI leader. 
Table 1 Four Leader Tactics to Solicit Creativity from Staff

\begin{tabular}{|c|c|}
\hline Leader tactic & Example \\
\hline No leader tactic $(n=3)$ & $\begin{array}{l}\text { No evidence of leader tactics used in } \\
\text { transcripts }\end{array}$ \\
\hline $\begin{array}{l}\text { Meeting ground rules } \\
(n=3)\end{array}$ & $\begin{array}{l}\text { "Ground rules: Participate. No talking over } \\
\text { each other. There's no such thing as a } \\
\text { stupid idea." } \\
\text { - Center } 2\end{array}$ \\
\hline $\begin{array}{l}\text { Brainstorming time } \\
(n=3)\end{array}$ & $\begin{array}{l}\text { "Let's now take } 20 \text { minutes of } \\
\text { brainstorming to discuss alternative ideas } \\
\text { for patient education" (topics changed for } \\
\text { every meeting) } \\
\text { - Center } 8\end{array}$ \\
\hline $\begin{array}{l}\text { Reflection on team } \\
\text { process }(n=3)\end{array}$ & $\begin{array}{l}\text { "Meeting process evaluation. Person } 1 \text { : } \\
\text { Team rating of } 9-\text { team worked efficiently } \\
\text { through all tasks but X was very quiet, } \\
\text { would like to hear more from her - she } \\
\text { knows a lot about this topic" - Center } 10\end{array}$ \\
\hline
\end{tabular}

Idea Creativity. Ideas were rated for creativity by an expert panel using the validated Consensual Assessment Technique. Experts familiar with the domain independently rate an idea for degree of novelty and usefulness, and ratings are multiplied for a creativity score. ${ }^{25}$ Five healthcare executives with at least 10 years of experience in administration (including QI) and graduate healthcare administration degrees were recruited as experts (60\% were female). Experts were not aware of other participants. ${ }^{25}$ Experts were emailed a survey containing vignette idea descriptions and were asked to rate each idea $(N=220)$ for novelty $(1=$ least novel to $5=$ most novel $)$ and usefulness $(1=$ least useful to $5=$ most useful $){ }^{25}$ Idea order was randomized. ${ }^{25}$ Novelty and usefulness scores were multiplied for a score from 5 to 25 , then divided by 5 for a creativity score out of $5(1=$ least creative to $5=$ most creative). ${ }^{25}$ We averaged the experts' scores for one score per idea. An intra-class correlation (ICC) was calculated between ratings ${ }^{26}\left(\mathrm{ICC}_{1, \mathrm{k}}=0.79\right)$, indicating a high degree of consistency acceptable for creativity assessments. ${ }^{25}$

Idea Implementation Outcome. Ideas were tracked over the course of the meetings to assess implementation. Implementation was defined when an idea was successfully transformed into a policy, process, or procedure by the organization, which was recorded in the meetings. ${ }^{27} \mathrm{We}$ noted whether each idea was implemented (coded as 1 , otherwise as 0 ) and the time elapsed (number of meetings) since the idea was first mentioned. Ideas not discussed in successive meetings or ideas discussed and rejected in a meeting were coded as not implemented. Right censoring occurred for ideas with no definitive outcome by the study end. ${ }^{28}$

Evolution of Implemented Ideas. The evolution of ideas implemented over the 18 months followed three distinct pathways. "Plug and Play" describes ideas implemented over 2 months or less, and were associated with low engagement on idea content. We coded an idea as low-engagement if the team did not discuss idea content, only the logistics for idea implementation. If the team discussed idea content plus implementation logistics, we coded the idea as having high engagement. We did not identify any ideas implemented over two meetings or less that garnered high engagement. "Slow Burn" describes ideas implemented over three meetings or more and were associated with low engagement. "Iterate and Generate" describes ideas implemented in three meetings or more, and were associated with high engagement. Table 2 shows the three pathways for all 220 ideas. We created dummy variables for analysis of the three pathways, with ideas not in a pathway as reference group.

Covariates. We included gender, professional role, and organizational tenure as staff characteristics that might influence ideas. Percentage of patients who were uninsured and patient visits per full-time employee captured differences in patient profile and workload per practice. We included a practice-level measure of psychological safety, the shared belief that the setting is safe for interpersonal risk taking, ${ }^{29}$ consisting of three items, including "In this team, if you make a mistake, it is often held against you" which were averaged and aggregated. This was included because it is critical to whether team members share creative ideas and organizations engage in learning required to implement new ideas. $^{30}$

\section{Analyses}

We calculated descriptive statistics and estimated multivariate multi-level regression models to assess associations between leader tactics, covariates, and dependent variables of idea creativity, implementation outcome, and evolution of implemented ideas. We used procedures in SAS 9.4 for each dependent variable. We clustered standard errors at practice and staff levels to account for multi-level data (ideas associated with staff, in practices) $)^{31,32}$ and calculated variance inflation factors to assess multi-collinearity.

First, we assessed the association between leader tactics and idea creativity, using the GLIMMIX procedure to account for multi-level data and continuous outcome variable. ${ }^{31} \mathrm{We}$ examined standardized coefficients and $p$ values to evaluate variable significance and interpret relative importance of each tactic on idea creativity. ${ }^{31}$ We assessed the association between leader tactics and idea implementation outcome using the PHREG procedure, ${ }^{31,32}$ and a multivariate Cox proportional hazards model, which incorporated time to implementation. ${ }^{28}$ To check the proportional hazards assumption, we conducted likelihood ratio tests for each variable; these tests indicated support for this assumption. ${ }^{32}$ We examined hazard ratios and confidence intervals to evaluate likelihood that 
Table 2 Three Pathways to Describe Evolution of Implemented Ideas

\begin{tabular}{|c|c|c|c|c|}
\hline Idea Evolution & $\begin{array}{c}\text { Team engagement with } \\
\text { idea content }\end{array}$ & $\begin{array}{l}\text { Idea outcome: } \\
\text { Implemented? }\end{array}$ & $\begin{array}{c}\text { Speed of } \\
\text { implementation }\end{array}$ & $\begin{array}{c}\text { Example of idea } \\
\text { (All with creativity score of 3) }\end{array}$ \\
\hline$\underset{\text { Time }}{\text { Plug and Play }}$ & Low & Implemented & $\begin{array}{c}\text { Fast: } \\
2 \text { months or less }\end{array}$ & $\begin{array}{c}\text { Schedule weekly } \\
\text { Nurse/PCP } \\
\text { care coordination meeting }\end{array}$ \\
\hline Slow Burn & Low & Implemented & $\begin{array}{c}\text { Slow: } \\
3 \text { months or more }\end{array}$ & $\begin{array}{c}\text { Create a resource list of } \\
\text { community partner } \\
\text { organizations }\end{array}$ \\
\hline$\underset{\text { Time }}{\longrightarrow}$ & High & Implemented & $\begin{array}{c}\text { Slow } \\
3 \text { months or more }\end{array}$ & $\begin{array}{c}\text { Integrate behavioral health } \\
\text { into care coordination } \\
\text { workflow }\end{array}$ \\
\hline
\end{tabular}

an idea associated with a leader tactic would be implemented over time. To assess association between leader tactics and evolution pathway for implemented ideas, we used the GENMOD procedure to perform a mixed model analysis. The association for each pathway was assessed in separate models, with pathway treated as a binarydependent variable. ${ }^{31,32} \mathrm{We}$ examined odds ratios and confidence intervals to evaluate likelihood that an idea associated with a leader tactic was associated with each idea evolution pathway.

\section{RESULTS}

Table 3 presents descriptive statistics. Average idea creativity was 2.47 out of $5(\mathrm{SD}=1.64)$ and $58 \%$ of ideas were implemented (23\% were Slow Burn, 21\% were Plug and Play, and $14 \%$ were Iterate and Generate idea evolution).

Table 4 shows results of the leader tactic and idea creativity analyses. Compared with no leader tactic, brainstorming was associated with a 0.19 standard deviation increase in idea creativity. Meeting ground rules and reflection on team process were not significantly associated with idea creativity. Professional role (PCPs and nurses), shorter organizational tenure, and greater psychological safety were associated with greater idea creativity.

Table 5 shows results of leader tactic and idea implementation analyses. Compared with no leader tactic, brainstorming and reflection on team process significantly increased hazard ratio for idea implementation by a factor of 1.2 , and 1.84 , respectively, whereas meeting ground rules was not significantly associated with idea implementation. Longer organizational tenure, more visits per FTE, and greater psychological safety were associated with greater idea implementation.

Table 6 shows results of the leader tactics and evolution for implemented ideas analyses. Model 1 shows that compared with no leader tactic, brainstorming increased odds ratio of "Plug and Play" idea evolution by a factor of 1.24. More visits per FTE was also significant. Model 2 shows that compared with no leader tactic, brainstorming, meeting ground rules, and reflection on team process were not significantly associated 
Table 3 Correlations of Key Variables $(N=220$ ideas)

\begin{tabular}{|c|c|c|c|c|c|c|c|c|c|c|c|c|c|c|c|}
\hline & Mean & S.D. & 1 & 2 & 3 & 4 & 5 & 6 & 7 & 8 & 9 & 10 & 11 & 12 & 13 \\
\hline 1. Idea creativity & 2.47 & 1.65 & & & & & & & & & & & & & \\
\hline 2. Plug and Play pathway & 0.21 & 0.41 & 0.40 & & & & & & & & & & & & \\
\hline 3. Slow Burn pathway & 0.23 & 0.42 & 0.20 & 0.28 & & & & & & & & & & & \\
\hline $\begin{array}{l}\text { 4. Iterate and } \\
\text { Generate pathway }\end{array}$ & 0.14 & 0.34 & 0.41 & $0.21 *$ & 0.20 & & & & & & & & & & \\
\hline 5. Idea Implementation & 0.58 & 0.48 & $-0.57^{* *}$ & $0.20 * *$ & $0.42 * *$ & $0.30 * *$ & & & & & & & & & \\
\hline $\begin{array}{l}\text { 6. Ground rules } \\
\text { tactic }(\%)\end{array}$ & 0.24 & 0.43 & 0.07 & 0.05 & 0.03 & 0.10 & 0.34 & & & & & & & & \\
\hline $\begin{array}{l}\text { 7. Brainstorming time } \\
\text { tactic }(\%)\end{array}$ & 0.30 & 0.47 & $0.54 *$ & $0.48 *$ & 0.03 & 0.21 & 0.19 & $0.36^{*}$ & & & & & & & \\
\hline $\begin{array}{l}\text { 8. Reflection on team } \\
\text { process tactic }(\%)\end{array}$ & 0.31 & 0.46 & 0.23 & 0.12 & 0.13 & $0.57 * *$ & $0.49 *$ & $0.34 * *$ & $0.42 * *$ & & & & & & \\
\hline $\begin{array}{l}\text { 9. Staff professional role } \\
\text { (ref: \% PCP) }\end{array}$ & 0.23 & 0.63 & 0.14 & 0.15 & 0.12 & 0.07 & 0.09 & 0.14 & 0.08 & 0.20 & & & & & \\
\hline $\begin{array}{l}\text { 10. Staff organizational } \\
\text { tenure }\end{array}$ & 4.02 & 1.14 & $-0.50^{* *}$ & 0.07 & 0.16 & 0.13 & 0.08 & 0.17 & 0.05 & 0.01 & 0.17 & & & & \\
\hline $\begin{array}{l}\text { 11. Staff gender } \\
(\text { ref: female }=1)\end{array}$ & 0.80 & 0.40 & 0.06 & 0.17 & 0.16 & 0.06 & 0.05 & 0.48 & 0.04 & 0.32 & 0.21 & 0.05 & & & \\
\hline $\begin{array}{l}\text { 12. Percentage of } \\
\text { patients uninsured }\end{array}$ & 0.07 & 0.05 & -0.08 & 0.10 & 0.04 & 0.14 & 0.04 & 0.02 & 0.04 & 0.36 & 0.11 & 0.10 & 0.08 & & \\
\hline $\begin{array}{l}\text { 13. Number of visits per } \\
\text { FTE ( } 6 \text { months) }\end{array}$ & 417.36 & 81.55 & 0.05 & 0.15 & 0.23 & 0.04 & 0.07 & 0.50 & 0.38 & 0.12 & 0.01 & 0.30 & 0.17 & 0.05 & \\
\hline $\begin{array}{l}\text { 14. Psychological safety } \\
\text { of work climate }\end{array}$ & 2.83 & 0.75 & $0.56^{*}$ & 0.09 & 0.07 & 0.17 & 0.09 & 0.30 & 0.41 & 0.42 & 0.07 & 0.31 & 0.07 & 0.22 & 0.03 \\
\hline
\end{tabular}

$* p<0.05 * * p<0.001$

with "Slow Burn" idea evolution. Model 3 shows that compared with no leader tactic, reflection on team process significantly increased odds ratio of the "Iterate and Generate" pathway by a factor of 1.73. Longer organizational tenure was also significant. Variance inflation factors for all models were below 6 and independent variables were below 2.50 (threshold is 10); multicollinearity was not an issue.

\section{DISCUSSION}

Our findings suggest that leader tactics have different effects on idea creativity, implementation outcome, and evolution of

Table 4 Results of Multi-level Regression Analysis of Leader Tactics on Idea Creativity $(N=220$ Ideas)

\begin{tabular}{ll}
\hline \hline Dependent variable: Idea creativity & \\
\hline Independent variables & $\beta$ (S.E.) \\
\hline No leader tactics & -reference- \\
Meeting ground rules & $0.10(0.19)$ \\
Brainstorming time & $0.19(0.03)^{*}$ \\
Reflection on team process & $0.03(0.17)$ \\
Covariates -individual & $0.09(0.07) *$ \\
Professional Role & $-0.21(0.04)^{* *}$ \\
Organizational tenure & $-0.03(0.18)$ \\
Gender & $-0.92(0.89)$ \\
Covariates-center level & $-0.01(0.01)$ \\
Percentage patients uninsured & $0.64(0.07) * *$ \\
Number of visits per FTE & 252.23 \\
Psychological Safety & \\
AIC statistic (goodness-of-fit) & \\
\hline$* p<0.05, * * p<0.001$ &
\end{tabular}

implemented ideas. Brainstorming was positively associated with idea creativity and "Plug and Play" idea evolution, which suggests this tactic promotes more creative, quickly implemented, low-engagement ideas. The association with idea creativity is consistent with studies linking brainstorming with higher creativity outside healthcare, ${ }^{18,} 33$ and extends past research by showing this tactic is more effective than other tactics in promoting creativity. The directive to generate creative ideas rapidly may promote divergent thinking needed for creativity. ${ }^{18}$ The evolution and implementation outcome results indicate that more creative ideas can also be implemented quickly, with low-engagement on the

Table 5 Results of Cox Proportional Hazards Model Relating Leader Tactics to Idea Implementation ( $N=220$ Ideas)

\begin{tabular}{ll}
\hline \hline Dependent variable: Idea implementation & \\
\hline Independent variables & $\begin{array}{l}\text { Hazard } \\
\text { ratio (CI) }\end{array}$ \\
\hline No leader tactics & -reference- \\
Meeting ground rules & $0.91(0.59-1.41)$ \\
Brainstorming time & $1.20(1.05-1.37)^{*}$ \\
Reflection on team process & $1.84(1.09-3.09)^{* *}$ \\
Covariates - individual idea submitter & \\
Professional role (reference: & $0.95(0.81-1.02)^{*}$ \\
primary care provider) & $1.14(1.01-1.28)^{* *}$ \\
Organizational tenure & $1.24(0.81-1.89)$ \\
Gender (reference: female) & \\
Covariates - center level & $0.05(0.03-0.07)$ \\
Percentage of patients uninsured & $1.10(1.00-1.14)^{* *}$ \\
Number of visits per full-time equivalent & $1.04(1.01-1.39)^{*}$ \\
Psychological safe work climate & 248.67 \\
AIC statistic (goodness-of-fit) & \\
\hline
\end{tabular}

$* p<0.05, * * p<0.001$ 
Table 6 Results of Cox Proportional Hazards Models Relating Leader Tactics to Idea Evolution Pathways $(N=220$ Ideas)

\begin{tabular}{|c|c|c|c|}
\hline \multicolumn{4}{|c|}{ Dependent variable: Idea evolution pathway } \\
\hline \multirow[b]{2}{*}{ Independent variables } & \multirow{2}{*}{$\frac{\text { Plug and Play }(N=220 \text { ideas })}{\text { Odds ratio }(\mathrm{CI})}$} & \multirow{2}{*}{$\frac{\text { Slow Burn }(N=220 \text { ideas })}{\text { Odds ratio }(C I)}$} & \multirow{2}{*}{$\frac{\text { Iterate and Generate }(N=220 \text { ideas })}{\text { Odds ratio }(\mathrm{CI})}$} \\
\hline & & & \\
\hline No leader tactics & -reference- & -reference- & -reference- \\
\hline Meeting ground rules & $0.97(0.25-2.18)$ & $0.49(0.33-1.73)$ & $0.67(0.54-1.59)$ \\
\hline Brainstorming time & $1.24(1.12-1.46)^{*}$ & $0.66(0.44-1.18)$ & $0.98(0.83-1.94)$ \\
\hline Reflection on team process & $0.71(0.24-1.25)$ & $0.73(0.49-1.21)$ & $1.73(1.27-1.96)^{*}$ \\
\hline \multicolumn{4}{|c|}{ Covariates - individual idea submitter } \\
\hline Professional role & $0.46(0.18-0.75)$ & $0.84(0.67-1.05)$ & $0.91(0.28-1.94)$ \\
\hline Organizational tenure & $1.14(0.88-1.47)$ & $1.04(0.89-1.13)$ & $1.78(1.23-2.54)^{* *}$ \\
\hline Gender & $0.27(0.07-0.96) *$ & $1.16(0.76-1.77)$ & $0.08(0.32-1.54)$ \\
\hline \multicolumn{4}{|l|}{ Covariates - center level } \\
\hline Percentage patients uninsured & $0.02(0.01-1.54)$ & $0.01(0.00-0.02) *$ & $0.12(0.09-1.01)$ \\
\hline Number of visits per FTE & $1.02(1.01-1.20)^{* *}$ & $1.01(0.87-1.02) *$ & $0.86(0.74-1.01)$ \\
\hline Psychological safety & $0.88(0.50-1.54)$ & $0.63(0.71-1.3)$ & $1.19(0.74-2.95)$ \\
\hline AIC statistic (goodness-of-fit) & 268.11 & 149.51 & 131.88 \\
\hline
\end{tabular}

$*_{p}<0.05, * * p<0.001$

idea's content, but with a focus on the logistics of implementation. For brainstorming success, leaders need skill in facilitating discussion around a shared purpose and enabling free flows of ideas such as allowing members to talk uninterrupted without fear of judgment to protect high-creativity ideas and promote rapid implementation. ${ }^{34,} 35$

Reflection on team process was positively associated with idea implementation and "Iterate and Generate" idea evolution, characterized by slower idea implementation with high team engagement about idea content. The ideas generated were less creative, however. No prior empirical study tested the effect of this tactic on our dependent variables, although theories suggest groups that reflect on their process may emphasize their collaborative output, ${ }^{17}$ and less creative ideas sustain more discussion over time as they are less likely to be criticized. ${ }^{36}$ Our work extends this by providing evidence to support the theory of less creativity in reflective teams, in a single study, and in healthcare QI.

There was not a significant association between meeting ground rules and idea creativity, evolution, or implementation. It may be that ground rules were used in teams where status differences were not prominent and had little effect. Future work should examine meeting ground rules to examine whether their effectiveness is conditional on other characteristics such as status differences.

Although we found a relationship between leader tactics and idea processes, we cannot determine a causal relationship. It is possible that leader tactics are indicative of practice dynamics, which we addressed by controlling for practice characteristics. Although only one leader tactic was listed in the minutes per practice, leaders may have used tactics not recorded. Nevertheless, this study suggests leaders should select tactics depending on their priorities. For some organizational challenges, the creativity imperative is urgent: existing approaches are insufficient, and rapidly implemented, creative ideas may be necessary for improvement. ${ }^{12}$
Preventing disruption to the status quo and stability of groups in the organization may be less important than the need for change. ${ }^{37}$ Leaders might consider employing brainstorming for these circumstances.

When circumstances suggests the value of incremental changes and deliberate problem solving, ${ }^{38,39}$ promoting commitment over longer periods of time for idea implementation, and fostering engagement, discussion and evaluation of ideas with other characteristics (e.g., external environment fit) may be more important. ${ }^{39,}{ }^{40}$ Leaders might consider employing reflection on team process for these circumstances, which emphasizes group process over rapid change, which may be desirable for leaders facing challenges requiring deep analysis. ${ }^{41}$ Leaders must be skilled at encouraging teams to notice the process and behaviors of teamwork, such as communication and the value of shared ideas. ${ }^{34}$ This work expands our understanding of how leaders facilitate QI, ${ }^{12}$ and suggests leaders employ tactics appropriate to their organizational goals.

This work contributes to implementation science literature that underscores the importance of "bottom up" efforts in change processes as a complement to "top down" QI interventions. ${ }^{42,}{ }^{43}$ Healthcare teams play a critical role in the implementation of top-down approaches, including the implementation of evidence-based interventions ${ }^{44}$ and public policy responses. ${ }^{42}$ Research has clarified how critical their ownership of implementation is, but has neglected examination of how healthcare teams generate QI ideas that form interventions to be implemented, despite this being viewed as critical to implementation success. ${ }^{43}$ Even less research has examined how clinicians and staff generate ideas, though there is often an organizational mandate to do so. ${ }^{42}$

Our findings have implications for QI and implementation. For QI, it implies that on-the-ground improvement, specifically the generation and implementation of QI ideas, may complement research-generated evidence 
implemented in a "top-down" fashion. ${ }^{43,44}$ Composition of on-the-ground teams matter: team members with shorter tenure were associated with greater idea creativity and longer tenure was associated with idea implementation. Both processes are critical. For QI leaders, leader tactics examined suggest optimal methods to foster engagement in QI by clinicians and staff under different conditions. For implementation researchers, leader tactics are strategies that can spread beyond a single setting, and can promote behavior change within primary care that can integrate into routine practice. Our findings address core issues at the nexus of implementation science and QI that advances the progress of primary care improvement.

Acknowledgments: The authors thank the study participants, research partners, and leadership of the system of community health practices for their willingness to be involved in the research. The authors thank conference participants at the Academy of Management and AcademyHealth for feedback. This project was supported by the Agency for Healthcare Research and Quality (AHRQ)-U18 HSO16978-Consumer Assessment of Healthcare Providers and Systems (CAHPS) IV.

Corresponding Author: Yuna S. H. Lee, PhD, MPH; Columbia University Mailman School of Public Health, New York, NY, USA (e-mail: ys12118@cumc.columbia.edu).

\section{Compliance with Ethical Standards:}

Conflict of Interest: The authors declared no potential conflicts of interest with respect to the research, authorship, and/or publication of this article.

\section{REFERENCES}

1. Institute of Medicine. The Learning Healthcare System. Washington, DC: The National Academies Press; 2007.

2. Institute of Medicine. Best care at lower cost: the path to continuously learning health care in America. Washington, DC: National Academies Press; 2012.

3. Grumbach $\mathbf{K}$, Bodenheimer T. Can Health Care Teams Improve Primary Care Practice? JAMA. 2004;291(10):1246-1251.

4. Bodenheimer T, Sinsky C. From triple to quadruple aim: care of the patient requires care of the provider. Ann Fam Med. 2014;12(6):573-576.

5. Millar R. Framing quality improvement tools and techniques in healthcare the case of improvement leaders' guides. J Health Organ Manag. 2013;27(2):209-224.

6. Lee YSH, Cleary PD, Nembhard IM. Fostering Implementation of Staff's Creative Ideas to Improve Patient Care Experiences. Acad Manag Proc. 2017;2017(1).

7. Parker L, Kirchner J, Bonner L, et al. Creating a quality-improvement dialogue: Utilizing knowledge from frontline staff, managers, and experts to foster health care quality improvement. Qual Health Res. 2009;19(2).

8. Puccio GaC J. . Organizational Creativity: A Systems Approach. In: Kaufman J. and Sternberg, R., ed. The Cambridge Handbook of Creativity: Cambridge University Press; 2010.

9. Boulgarides J, Cohen W. Leadership Style vs. Leadership Tactics. J Appl Manag Entrep. 2001;6(1):59-73.

10. Amabile T. A Model of Creativity and Innovation in Organizations. Res Organ Behav. 1988;10:123-167.

11. Perry-Smith JE, Mannucci PV. From creativity to innovation: The social network drivers of the four phases of the idea journey. Acad Manag Rev. 2017;42(1):53-79.
12. Amabile T, Schatzel E, Moneta G, Kramer S. Leader behaviors and the work environment for creativity: Perceived leader support. Leadersh Q 2004; 15(1):5-32.

13. Deci E, Connell J, Ryan R. Self-Determination in a Work Organization. J Appl Psychol. 1989;74(4):580-590.

14. Frese M, Teng E, Wijnen C. Helping to improve suggestion systems: predictors of making suggestions in companies. J Organ Behav. 1999;20: 1139-1155.

15. Jung D, Chow C, Wu A. The role of transformational leadership in enhancing organizational information: Hypotheses and some preliminary findings. Leadersh Q. 2003;14:525-544.

16. Shin $\mathbf{S}$, Zhou $\mathbf{J}$. When is educational specialization heterogeneity related to creativity in research and development teams? Transformational leadership as a moderator. J Appl Psychol. 2007;92(6):1709-1721.

17. Sawyer R. Individual and Group Creativity. In: Kaufman JaS, R., eds. New York, The Cambridge Handbook of Creativity: Cambridge Unviersity Press 2010.

18. Sutton RI, Hargadon AB. Brainstorming Groups in Context: Effectiveness in a Product Design Firm. Adm Sci Q. 1996;41(4):685-718.

19. Scott G, Leritz L, Mumford $\mathbf{M}$. The effectiveness of creativity training: A quantitative review. Creat Res J. 2004;16(4):361-388.

20. Miles MB, Huberman AM. Qualitative data analysis. London: Sage Publications; 1994.

21. Strauss A, Corbin J. Basics of qualitative research: Techniques and procedures for developing grounded theory. Thousand Oaks, CA: Sage Publications; 1990.

22. Binnewies $\mathbf{C}$, Ohly $\mathbf{S}$, Sonnentag $\mathbf{S}$. Taking personal initiative and communicating about ideas: Why its important for the creative process and idea creativity. Eur J Work and Organ Psychol. 2007;16(4):432-455.

23. Yin RK. Case study research: Design and methods. Thousand Oaks, CA: Sage Publication; 2003.

24. Campbell J, Quincy C, Osserman J, Pedersen O. Coding In-depth Semistructured Interviews: Problems of Unitization and Intercoder Reliability and Agreement. Sociol Methods Res. 2013;42(3):294-320.

25. Amabile T. Social-Psychology of Creativity - a Consensual Assessment Technique. J Pers Soc Psychol 1982;43(5):997-1013.

26. Plucker JaM M. Assessment of Creativity. In: Kaufman J and Sternberg, R., ed. The Cambridge Handbook of Creativity: Cambridge University Press. 2010

27. Baer M. Putting Creativity to Work: The Implementation of Creative Ideas in Organizations. Acad Manag J. 2012;55(5):1102-1119.

28. Hedeker D, Gibbons R. Longitudinal Data Analysis. New Jersey: Wiley, Inc.; 2006.

29. Edmondson A. Psychological safety and learning behavior in work teams. Admin Sci Quart. 1999;44(2):350-383.

30. Tucker AL, Nembhard IM, Edmondson AC. Implementing New Practices: An Empirical Study of Organizational Learning in Hospital Intensive Care Units. Manag Sci. 2007;53(6):894-907.

31. Littell R, Stroup W, Milliken G, Wolfinger R, Schabenberger $\mathbf{O}$. SAS for Mixed Models, Second Edition. 2006.

32. Lin DY, Wei LJ. The Robust Inference for the Cox Proportional Hazards Model. J Am Stat Assoc. 1989;84(408):1074-1078.

33. Taggar S. Individual creativity and group ability to utilize individual creative resources: A multilevel model. Acad Manag J. 2002;45(2):315330.

34. Kitson A, Harvey G, McCormack B. Enabling the implementation of evidence based practice: a conceptual framework. Qual Health Care. 1998;7(3):149-158.

35. Damschroder LJ, Aron DC, Keith RE, Kirsh SR, Alexander JA, Lowery JC. Fostering implementation of health services research findings into practice: a consolidated framework for advancing implementation science. Implement Sci. 2009;4:50.

36. Fleming L, Mingo, S., Chen, D. Collaborative brokerage, generative creativity and creative success. Adm Sci Q. 2007;52(3):32.

37. Gilson LL, Mathieu JE, Shalley SE, Ruddy TM. Creativity and Standardization: Complementary or Conflicting Drivers of Team Effectiveness? Acad Manag J. 2005;48(3):521-531.

38. Perry-Smith JE, Shalley CE. The social side of creativity: A static and dynamic social network perspective. Acad Manag Rev. 2003;28(1):89-106.

39. Unsworth K. Unpacking Creativity. Acad Manag Rev. 2001;26(2):289297-297.

40. Van de Van AH, Polley DE, Garud R, Venkataraman S. The innovation journey. Oxford: Oxford University Press; 1999. 
41. West M. Sparkling Fountains or Stagnant Ponds: An Integrative Model of Creativity and Innovation Implementation in Work Groups. Appl Psychol Int Rev. 2002;50(3):355-424.

42. Mukamel DB, Haeder SF, Weimer DL. Top-Down and Bottom-Up Approaches to Health Care Quality: The Impacts of Regulation and Report Cards. Annu Rev Public Health. 2014;35(1):477-497.

43. Thomann E, van Engen N, Tummers L. The Necessity of Discretion: A Behavioral Evaluation of Bottom-Up Implementation Theory. J Public Adm Res Theory. 2018;28(4):583-601.
44. Ogunlayi F, Britton P. Achieving a 'top-down' change agenda by driving and supporting a collaborative 'bottom-up' process: case study of a largescale enhanced recovery programme. BMJ Open Qual. 2017;6(2):e000008.

Publisher's Note: Springer Nature remains neutral with regard to jurisdictional claims in published maps and institutional affiliations. 